\title{
Prognostic Implications of Impaired Longitudinal Left Ventricular Systolic Function Assessed by Tissue Doppler Imaging Prior to Transcatheter Aortic Valve Implantation for Severe Aortic Stenosis
}

guglielmo gallone ( $\sim$ guglielmo.gallone@gmail.com )

University of Turin: Universita degli Studi di Torino

Francesco Bruno

Division of Cardiology, Department of Medical Science, AOU citta della Salute e della Scienza

Teresa Trenkwalder

Deutsches Herzzentrum München: Deutsches Herzzentrum Munchen

Fabrizio D'Ascenzo

Division of Cardiology, Department of Medical Sciences, Citta della Salute e della Scienza, University of Turin, Italy

\section{Fabian Islas}

Hospital CLinico San Carlos, IDISSC, and Universidad Complutense de Madrid, Spain

Pier Pasquale Leone

Humanitas Clinical and Research Center IRCCS, Rozzano, Milan, Italy

\section{Phillip Nicol}

Deutsches Herzzentrum München des Freistaates Bayern: Deutsches Herzzentrum Munchen

\section{Costanza Pellegrini}

Deutsches Herzzentrum München: Deutsches Herzzentrum Munchen

\section{Enrico Incaminato}

Division of Cardiology, Department of Medical Sciences, Citta della Salute e della scienza, University of Turin, Italy

Pilar Jimenez-Quevedo

Hospital CLinico San Carlos, IDISSC and Universidad Complutense de Madrid, Spain

Hector Alfonso Alvarez Covarrubias

Deutsches Herzzentrum München: Deutsches Herzzentrum Munchen

\section{Renato Bragato}

Humanitas Clinical and Research Center IRCCS, Rozzano

\section{Alessandro Andreis}

Division of Cardiology, Department of Medical Sciences, Citta della Salute e della Science, University of Turin, Italy

\section{Stefano Salizzoni}


Division of Cardiac Surgery, Department of Medical Sciences, Citta della Salute e della Scienza, University of Turin, Italy

\section{Mauro Rinaldi}

Division of Cardiac Surgery, Department of Medical Sciences, Citta della Salute e della Scienza, University of Turin, Italy

\section{Adnan Kastrati}

Deutsches Herzzentrum München: Deutsches Herzzentrum Munchen

\section{Federico Conrotto}

Division of Cardiology, Department of Medical Sciences, Citta della Salute e della Scienza, university of Turin, Italy

\section{Michael Joner}

Deutsches Herzzentrum München: Deutsches Herzzentrum Munchen

\section{Giulio Stefanini}

humanitas Clinical and Research Center IRCCS Rozzano-Milan

\section{Luis Nombela-Franco}

Hospital Clinico San Carlos, IDISSC and Universidad Complutense de Madrid, Spain

\section{Erion Xhepa}

Deutsches Herzzentrum München: Deutsches Herzzentrum Munchen

\section{Javier Escaned}

hospital Clinico San Carlos,IDISSC and universidad Complutense de Madrid, Spain

\section{Gaetano Maria De Ferrari}

Division of Cardiology, Department of Medical Sciences, Citta della salute e della Scienza, university of Turin, Italy

\section{Research Article}

Keywords: Aortic stenosis, transcatheter aortic valve replacement, tissue doppler imaging, longitudinal systolic function, peak systolic mitral annular velocity, risk prediction

Posted Date: October 18th, 2021

DOl: https://doi.org/10.21203/rs.3.rs-946297/v1

License: (c) (i) This work is licensed under a Creative Commons Attribution 4.0 International License. Read Full License

Version of Record: A version of this preprint was published at The International Journal of Cardiovascular Imaging on January 10th, 2022. See the published version at https://doi.org/10.1007/s10554-021-025192. 


\section{Abstract}

\section{Background}

Change in longitudinal left ventricular (LV) systolic function serves as an early marker of the deleterious effect of aortic stenosis (AS) and other cardiac comorbidities on cardiac function. We explored the prognostic value of tissue doppler imaging (TDI)-derived longitudinal LV systolic function, defined by the peak systolic average of lateral and septal mitral annular velocities (average $S^{\prime}$ ) among symptomatic patients with severe AS undergoing transcatheter aortic valve implantation (TAVI).

Methods and results

297 unselected patients with severe AS undergoing TAVI at three european centers with available average $S^{\prime}$ at preprocedural echocardiography were retrospectively included. The primary endpoint was the Kaplan Meier estimate of all-cause mortality. After a median 18 months (IQR 12-18) follow-up, 36 (12.1\%) patients died. Average S' was associated with all-cause mortality (per $1 \mathrm{~cm} / \mathrm{sec}$ decrease: HR 1.29, 95\%Cl 1.03-1.60, $p=0.025$ ), being the cut-off of $6.5 \mathrm{~cm} / \mathrm{sec}$ the most accurate. Patients with average $S^{\prime}<6.5$ $\mathrm{cm} / \mathrm{sec}(55.2 \%)$ presented characteristics of more advanced LV remodeling and functional impairment along with higher burden of cardiac comorbidities, and experienced higher all-cause mortality $(17.6 \% \mathrm{vs}$. $7.5 \%, \mathrm{p}=0.007$ ), also when adjusted for in-study outcome predictors (adj-HR: $2.69,95 \% \mathrm{Cl} 1.22-5.93$, $\mathrm{p}=0.014)$. Results were consistent among patients with preserved ejection fraction, normal-flow AS, highgradient AS and in those without LV hypertrophy.

Conclusions

Longitudinal LV systolic function assessed by average $S^{\prime}$ is independently associated with long-term allcause mortality among TAVI patients. An average $S^{\prime}$ below $6.5 \mathrm{~cm} / \mathrm{sec}$ best defines clinically meaningful reduced longitudinal systolic function and may aid clinical risk stratification in these patients.

\section{Introduction}

Left ventricular (LV) responses to aortic valve stenosis (AS) are associated with impaired prognosis. The chronic increase in afterload imposed by AS leads to LV remodeling to counteract the elevated wall stress ${ }^{1}$. When LV hypertrophy is unable to fully compensate for the pressure overload, reduced longitudinal shortening ensues with impairment of myocardial contractility, well before overt global systolic dysfunction becomes apparent ${ }^{2}$. The described response is highly heterogenous, influenced by factors including sex, arterial systemic hypertension, and coronary artery disease and amyloidosis, which

are highly prevalent in AS and may interact with the clinical benefit of aortic valve replacement ${ }^{3-6}$.

By integrating information on LV responses to AS and concomitant cardiac comorbidities, longitudinal systolic function may provide important prognostic value in patients with AS in whom transcatheter aortic valve implantation (TAVI) is being considered as a treatment ${ }^{7}$. While this concept has been proven 
for speckle tracking-derived systolic global longitudinal strain ${ }^{8,9}$, no study explored the prognostic role of tissue doppler imaging (TDI)-derived longitudinal systolic function among symptomatic patients with severe AS prior to TAVI.

TDI-derived peak systolic velocity at the mitral annulus ( $\left.\mathrm{S}^{\prime}\right)$ is a widely available index with numerous advantages for the outlined purpose: it is easily obtainable and highly reproducible, sensitive to early longitudinal contractile dysfunction ${ }^{10}$, and with demonstrated prognostic predictive value in cardiac conditions including coronary artery disease, mitral regurgitation and heart failure with preserved ejection fraction (EF) ${ }^{10-12}$. Furthermore, the use of $S^{\prime}$ may help in circumventing several limitations of speckle tracking-derived strain parameters, including difficulty of application, inter-vendor reference values heterogeneity and inter-observer variability ${ }^{13}$, making it a powerful bed-side tool for the clinician.

The present study aims to characterize the clinical and echocardiographic correlates of TDI-derived peak systolic velocity at the mitral annulus and to assess its prognostic value among unselected symptomatic patients with severe AS undergoing TAVI.

\section{Methods}

\subsection{Study design}

Unselected patients with severe AS undergoing TAVI from January 2017 to December 2018 at three international Tertiary Centers (Deutsches Herzzentrum München, Munich, Germany; Hospital Clinico San Carlos, Madrid, Spain; Città della Salute e della Scienza Hospital, Turin, Italy) with available TDI-derived longitudinal systolic function measurements at preprocedural echocardiography were retrospectively included in this study.

TAVI was performed according to local expertise and standard techniques. All patients provided written informed consent before the procedure. The registry was approved by the local ethics committee and was conducted in accordance with the Declaration of Helsinki.

\subsection{Echocardiographic assessment and data collection}

Baseline clinical, echocardiographic and laboratory variables along with clinical follow-up data were prospectively collected at each institution and retrospectively analyzed. Baseline echocardiography was performed in all patients within 3 months before the TAVI procedure. When available, echocardiographic follow-up data were also collected. The echocardiographic evaluation was independently performed by experienced cardiologists who were blinded to patient outcomes.

Echocardiographic exams were performed according to the guidelines of the American Society of Echocardiography ${ }^{14}$. LV volumes and LV mass were determined utilizing standard techniques. LV EF was measured using a biplane measurement from the apical views using the modified Simpson's method. Trans-mitral early $(E)$ and late $(A)$ velocities and $E$ wave deceleration time were measured by spectral 
pulsed-wave Doppler ultrasound at the mitral leaflet tips. TDI was performed adjusting gain and frame rate to get an appropriate tissue characterization. Peak systolic (S') and early (E') velocities of the lateral and medial mitral annulus were measured by pulsed-wave TDI from the apical four-chamber view and the average was calculated (Figure 1). The aortic valve area was calculated by the continuity equation, and the maximum pressure gradient across the restrictive orifice was estimated by the modified Bernoulli equation. Mean transaortic pressure gradient was calculated averaging the instantaneous gradients over the ejection period on the continuous-wave Doppler recordings. LV stroke volume was calculated multiplying the systolic velocity-time integral at the LV outflow tract per its area and was indexed to body surface area (SVi). The severity of valvular regurgitation was determined on a qualitative scale (mild, moderate, and severe), according to the current guidelines for the management of patients with valvular heart disease $\mathrm{e}^{15}$.

The Society for Thoracic Surgery Predictive Risk of Mortality (STS PROM) score ${ }^{16}$ and the EuroSCORE $\|{ }^{17}$ were prospectively calculated.

\subsection{Study endpoints}

The primary endpoint was all-cause mortality at follow-up. Secondary endpoints were a composite of allcause mortality and hospitalization for heart failure (HF) at last follow-up and Valve Academic Research Consortium (VARC)-2 defined adverse outcomes assessed at 30 days ${ }^{18}$.

\subsection{Statistical analysis}

Categorical variables are expressed as number and percentages, continuous variables are expressed as mean \pm standard deviation or median and interquartile range (IQR) as appropriate. Unpaired t test or nonparametric Mann-Whitney $U$ test were used for comparisons of continuous variables and chi-square test was used for categorical variables. Peak systolic average of lateral and septal mitral annular velocities (average $S^{\prime}$ ) was analyzed both continuously and at the best cut-off value to predict the primary endpoint determined by Receiver Operating Characteristic (ROC) curve analysis applying the Youden's $J$ statistic.

Kaplan-Meier and Cox proportional hazard models were performed to evaluate cumulative event rates of the primary endpoint at long-term follow-up and results are presented as hazard ratio (HR) and 95\% confidence intervals (Cls). To produce meaningful outcome estimates, maximum follow-up length was truncated at 18 months.

A multivariate Cox proportional hazards analysis was performed to assess the independent association of average $S^{\prime}$ with all-cause mortality, and all-cause mortality or HF hospitalization. All the variables with a univariate $p<0.10$ were entered into the models.

A $p<0.05$ was considered statistically significant. Statistical analyses were conducted using SPSS (version 24.0, SPSS Inc., Chicago, Illinois, US). 


\section{Results}

\subsection{Study population and outcomes}

Overall, 297 unselected patients with severe AS undergoing TAVI and with available TDI-derived longitudinal systolic function measurements constituted the study population. Baseline clinical and echocardiographic characteristics are described in Tables 1 and $\mathbf{2}$.

The mean age was $81 \pm 6$ years and 150 (50.5\%) patients were female. Mean STS PROM was $5.5 \pm 4.4 \%$ and mean Euroscore II was $6.1 \pm 5.8 \%$.

At echocardiographic assessment, $25 \%$ of the patients had reduced $E F(E F<50 \%), 74.3 \%$ had LV hypertrophy (LV mass index $\geq 115 \mathrm{gr} / \mathrm{m}^{2}$ for male, $\geq 95 \mathrm{gr} / \mathrm{m}^{2}$ for female), $39.5 \%$ had low-flow AS (SVi $<35 \mathrm{ml} / \mathrm{mq}$ ) and $36.7 \%$ had low-gradient AS (mean AS gradient $<40 \mathrm{mmHg}$ ).

After a median follow-up of 18 months (IQR 12-18 months), 36 (12.2\%) patients died, and 44 (14.8\%) died or were hospitalized for HF. Procedural outcomes are reported in Supplementary Table 1 and short-term VARC-2 outcomes are reported in Table 3.

\subsection{TDI-derived longitudinal left ventricular systolic function}

Mean peak systolic average of lateral and septal mitral annular velocities (average $S^{\prime}$ ) was $6.2 \pm 1.6$ $\mathrm{cm} / \mathrm{sec}$. Average $\mathrm{S}^{\prime}$ was associated with increased all-cause mortality at last follow-up (per $1 \mathrm{~cm} / \mathrm{sec}$ decrease: HR 1.29, 95\% Cl 1.03-1.60, $p=0.025)$. The best average $S^{\prime}$ for all-cause mortality was 6.5 $\mathrm{cm} / \mathrm{sec}$, obtained from ROC analysis (area under the ROC $0.632,95 \% \mathrm{Cl} 0.538-0.726, \mathrm{p}=0.033$ ).

Patients with reduced average $S^{\prime}(<6.5 \mathrm{~cm} / \mathrm{sec}, 55.2 \%$ of the study population) had similar clinical characteristics to patients with $S^{\prime} \geq 6.5 \mathrm{~cm} / \mathrm{sec}$, except for more frequent prior myocardial infarction ( $19.5 \%$ vs $7.5 \%, p=0.004)$ and atrial fibrillation $(45.1 \%$ vs $25.6 \%, p=0.001)$ (Table 1$)$. At preprocedural echocardiography, patients with reduced average $S^{\prime}$ presented with characteristics of more advanced LV remodeling and functional impairment (Table 2). In particular, reduced EF (32.9\% vs. 9.2\%, p<0.001), LV hypertrophy ( $83.5 \%$ vs. $60.3 \%, p<0.001)$, low-flow AS (48.0\% vs. $31.4 \%, p=0.004)$ and low-gradient AS $(42.7 \%$ vs. $30.5 \%, p=0.021)$ were more frequent among patients with reduced average $S^{\prime}$.

Patients with reduced average $S^{\prime}$ had higher Kaplan Meier estimates of all-cause mortality $(17.6 \% \mathrm{vs}$. 7.5\%; HR 2.97, 95\% Cl 1.36-6.33, p=0.007) and all-cause mortality or HF hospitalization $(20.2 \%$ vs. $10.7 \%$; HR $2.02,95 \% \mathrm{Cl} 1.06-3.86, \mathrm{p}=0.027$ ) (Figure 2). Short-term outcomes were similar regardless of average $\mathrm{S}^{\prime}$ status (Table 3 ).

\subsection{Predictors for adverse clinical outcomes}

Multivariable models of predictors for all-cause mortality and of all-cause mortality or HF hospitalization at last follow-up are presented in Table 4. After multivariable adjustment, reduced average S' (adj-HR: 
2.69, $95 \% \mathrm{Cl} 1.22-5.93, \mathrm{p}=0.014$ ) and Euroscore II (per $1 \%$ increase: $1.05,95 \% \mathrm{Cl} 1.01-1.09, \mathrm{p}=0.009$ ) were independent predictors of all-cause mortality, while reduced average S' (Adj-HR 2.01, 95\% Cl 1.05-3.83, $\mathrm{p}=0.035$ ) and mean AS gradient (per $1 \mathrm{mmHg}$ decrease: $1.03,95 \% \mathrm{Cl} 1.01-1.06, \mathrm{p}=0.018$ ) were independent predictors of all-cause mortality or HF hospitalization.

\subsection{Association of reduced average $S^{\prime}$ with all-cause mortality in relevant subgroups}

Kaplan Meier estimates for the primary endpoint stratified by average $S^{\prime}$ among subgroups of EF, SVi, AS gradient and LV hypertrophy are presented in Figure 3. A reduced average $S^{\prime}$ remained independently associated with all-cause mortality among patients with less severe structural remodeling and functional impairment (preserved EF subgroup: adj-HR 2.98, 95\% Cl 1.24-7.16, $p=0.014$; normal flow subgroup: adjHR 4.39, 95\% Cl 1.44-13.40, $p=0.009$; high gradient AS subgroup: adj-HR 3.24, 95\% Cl 1.06-9.96, $\mathrm{p}=0.040$; no-LV hypertrophy subgroup: adj-HR 2.64, 95\% Cl 1.03-6.76, $\mathrm{p}=0.043)$.

\subsection{Prognostic relevance of average $S^{\prime}$ improvement following TAVI}

156 (52.5\%) patients had available post-TAVI echocardiography with average S' measurements (median 64 [IQR 42-83] days post-TAVI).

Of 80 patients with reduced average S' pre-TAVI, $40(50 \%)$ had average $S^{\prime}$ "normalization" ( $\left.\geq 6.5 \mathrm{~cm} / \mathrm{sec}\right)$ following TAVI. Patients experiencing average $S^{\prime}$ normalization had non significantly different all-cause mortality estimates as compared to patients with normal average S' pre-TAVI (13.8\% vs. $7.4 \%$, logrank $=0.263$ ), while patients with persistently reduced average $S^{\prime}$ had significantly higher all-cause mortality estimates $(22.6 \%$ vs. $7.4 \%, p=0.043)$.

\section{Discussion}

The main finding of our study is that, in patients with severe AS undergoing TAVI, impairment of longitudinal LV systolic function, estimated through average $S^{\prime}$ measurements, predicts medium-term allcause mortality. The association between average $S^{\prime}$ and mortality was independent from the patient's clinical profile and from the echocardiographic parameters of cardiac structure and function, and it was consistently observed among patient subgroups with less severe structural remodeling or functional impairment (including those with preserved EF, normal SVi, high gradient AS or no LV hypertrophy). For clinical purposes, an average $S^{\prime}$ below $6.5 \mathrm{~cm} / \mathrm{sec}$ best defines clinically meaningful reduced longitudinal LV systolic function in symptomatic severe AS.

This is the first study assessing the prognostic value of average $S^{\prime}$ among symptomatic patients with severe AS undergoing TAVI. A previous study by Stewart et al tested the role of average $S^{\prime}$ among 183 asymptomatic patients with moderate to severe AS, failing to demonstrate independent predictive value for clinical deterioration after accounting for the severity of $A S^{4}$. In such study, average $S^{\prime}$ was higher than in our population (median [IQR]: $6.7[6.0-7.9] \mathrm{cm} / \mathrm{sec}$ vs. 6.1 [5.1-7.3] $\mathrm{cm} / \mathrm{sec}$ ) coherently with the different phase of AS natural history. Major differences between both studies may explain the 
discrepancy in the results. In addition to a much larger study population $(n=297)$, our study included only symptomatic patients with severe AS eligible for TAVI, while in the study by Stewart only $62 \%$ eventually underwent surgical aortic valve replacement. Moreover, mechanisms of reduced longitudinal contractility may vary over the natural history of AS. Indeed, the observation that the association of average $S^{\prime}$ with clinical deterioration was fully accounted by AS severity among asymptomatic moderate to severe AS patients suggests that, when afterload-mismatch is the mechanism of decreased longitudinal systolic function, no prognostic implication ensues ${ }^{4}$. Conversely, in more advanced AS disease, maladaptive mechanisms may underlie the longitudinal systolic function impairment entailing worse outcome despite valve replacement ${ }^{19,20}$.

Average $S^{\prime}$ was the sole prognostic echocardiographic predictor along with the patient's clinical risk profile as assessed by the Euroscore II tool. This finding mirrors those of a prior study in which longitudinal systolic function as assessed by global longitudinal strain recapitulated the mortality impact of all other myocardial and valve structural and functional echocardiographic parameters ${ }^{21}$.

In our study, reduced average $S^{\prime}$ was more frequently observed among patients with previous $\mathrm{Ml}$, moderate to severe mitral or tricuspid regurgitation and atrial fibrillation. This highlights how average $S^{\prime}$ may reflect the summative effect of different pathophysiological mechanisms related to frequently existing conditions in patients with AS that also affect myocardial function. Of note, the information obtained predicts patient prognosis despite valve replacement. A reduced average $S^{\prime}(<6 \mathrm{~cm} / \mathrm{sec})$ has been proposed as a highly accurate marker (Sensitivity $100 \%$, Specificity $57 \%$ ) to screen TAVI candidates for transthyretin cardiac amyloidosis, outperforming speckle-strain imaging parameters ${ }^{3}$. This condition may be prevalent in up to $16 \%$ patients with severe AS undergoing $\mathrm{TAVI}^{3}$ and may be associated with worse outcomes following valve replacement ${ }^{6}$, an observation that may be indirectly reflected by the findings of the present study.

Our results were consistent among patients with preserved EF, normal SVi or high gradient AS. These AS subgroups are overall associated with better outcomes following TAVI ${ }^{5,22-24}$ and show no apparent pump dysfunction in most patients, especially in case of compensatory LV hypertrophy ${ }^{25}$. Our findings reinforce the concept of impaired longitudinal myocardial shortening as an early marker of systolic dysfunction and establish its prognostic value among symptomatic severe AS patients undergoing TAVI also when isolated reduced average $S^{\prime}$ is found.

In exploratory analyses, we evaluated the clinical significance of the change in average S' following TAVI. Among patients with pre-TAVI reduced average $S^{\prime}$, longitudinal systolic function recovered in one out of two patients (post-TAVI average $S^{\prime} \geq 6.5 \mathrm{~cm} / \mathrm{sec}$ ). Long-term mortality in patients with recovered average $S^{\prime}$ was similar to those of patients with pre-TAVI preserved average $S^{\prime}$, while prognosis remained poorer for patients with persistently reduced $S^{\prime}$. This finding suggests once again that several mechanisms may underlie reduced contractile function in severe AS, entailing differential prognostic implications 1,19,20,26,27. More importantly, it adds up to current literature that demonstrated LV reverse remodeling following TAVI 
to be a positive marker of favorable long-term outcome $e^{27-29}$ and it points at post-TAVI average $\mathrm{S}^{\prime}$ as a reliable echocardiographic feature able to define the patient's trajectory also within the preserved EF population and at an early assessment, thus providing an advantage over post-TAVI LV mass and EF which recover throughout a longer time course ${ }^{27}$.

In the present study we assessed longitudinal systolic function by average S', a TDI-derived parameter of LV long-axis motion measured at the mitral annular level. This approach lacks the ability to reflect segmental functional abnormalities, is affected by signal noise and requires accurate parallel alignment of the Doppler beam with myocardial motion direction. While these drawbacks are at least partly overcome by speckle-tracking echocardiography, whose ability to risk stratify patients in symptomatic severe AS patients has been previously demonstrated ${ }^{21}$, the latter is less practical, presents a longer learning curve and requires proprietary software with inter-vendor variability in reference values ${ }^{13}$. To this regard, TDI remains a widely available tool, with great ease of use and high reproducibility which may provide powerful clinical information to orientate risk stratification and patient management across a variety of clinical conditions. Of note, the segmental nature of speckle tracking-derived strain parameters (of clinical relevance across several myocardial diseases) seems to provide limited advantage in severe AS where impaired longitudinal function is primarily reflected at the basal myocardial level. Indeed, basal longitudinal fibers are more exposed to the increased interventricular pressure during isovolumic contraction and are firstly affected by impaired longitudinal shortening as compared to mid-apical segments. This concept is proved on clinical ground, with previous demonstrations of basal longitudinal strain as a more powerful predictor of symptoms and outcomes as compared to global longitudinal strain in $A S^{30,31}$.

\section{LIMITATIONS}

The findings of this study should be interpreted in the light of several limitations. First, this was a retrospective registry of clinical practice data. In front of the inherent limitations of study design and missing data, our findings have the advantage of generalizability to the real-world clinical setting. Second, the study sample size was relatively small. However, this represents the largest available study of average $S^{\prime}$ in symptomatic severe AS, with consistent results across study subgroups and a grounded physiopathological rationale. Third, we did not assess the independent prognostic impact of average $S^{\prime}$ against speckle-tracking derived longitudinal strain. As discussed above, this was not the scope of the present analysis and the findings of the study should be interpreted and applied within the boundaries of the study design.

\section{Conclusions}

TDI-derived peak systolic average of lateral and septal mitral annular velocities is associated with longterm all-cause mortality among unselected patients with symptomatic severe AS undergoing TAVI. In this population, an average $\mathrm{S}^{\prime}$ below $6.5 \mathrm{~cm} / \mathrm{sec}$ best defines clinically meaningful reduced longitudinal LV systolic function and may aid clinical risk stratification. 


\section{Abbreviations}

AS = aortic stenosis

$\mathrm{Cl}=$ confidence interval

$\mathrm{EF}=$ Ejection Fraction

$\mathrm{HF}=$ Heart failure

$\mathrm{HR}=$ hazard ratio

$\mathrm{IQR}=$ Interquartile Range

$\mathrm{LV}=$ Left ventricle

STS PROM = Society for Thoracic Surgery Predictive Risk of Mortality

$\mathrm{TAVI}=$ transcatheter aortic valve implantation

TDI = Tissue Doppler Imaging

VARC $=$ Valve Academic Research Consortium

\section{Declarations}

\section{Funding}

This research did not receive any specific grant from funding agencies in the public, commercial, or notfor-profit sectors.

Conflicts of interest/Competing interests (include appropriate disclosures)

None

\section{Availability of data and material (data transparency)}

Data will be made available to interested parties by the corresponding author upon reasonable request.

\section{Code availability}

Not applicable

\section{Ethics approval}

The registry was approved by the local ethics committee and was conducted in accordance with the Declaration of Helsinki. 


\section{Consent to participate (include appropriate statements)}

All patients provided written informed consent before the procedure.

\section{Consent for publication}

\section{References}

1. Carabello BA, Paulus WJ. Aortic stenosis. Lancet Elsevier Ltd; 2009;373:956-966.

2. Rasmussent BS, Hansen OK, Pilegaard HK, Kristensen LH. Left ventricular systolic and diastolic function in aortic stenosis. Heart 1997;1977-1987.

3. Narotsky DL, Hamid N, Khalique OK, Casta A, Morgenstern R, Deluca A, Rubin J, Chiuzan C, Nazif T, Vahl T, George I, Kodali S, Leon MB, Hahn R, Bokhari S, Maurer MS. Unveiling transthyretin cardiac amyloidosis and its predictors among elderly patients with severe aortic stenosis undergoing transcatheter aortic valve replacement. Eur Hear J 2017;1-9.

4. Stewart RAH, Kerr AJ, Whalley GA, Legget ME, Zeng I, Williams MJA, Lainchbury J, Hamer A, Doughty R, Richards MA, White HD. Left ventricular systolic and diastolic function assessed by tissue Doppler imaging and outcome in asymptomatic aortic stenosis. Eur Heart J 2010;31:2216-2222.

5. Ribeiro HB, Lerakis S, Gilard M, Cavalcante JL, Makkar R, Herrmann HC, Windecker S, EnriquezSarano M, Cheema AN, Nombela-Franco L, Amat-Santos I, Muñoz-García AJ, Garcia del Blanco B, Zajarias A, Lisko JC, Hayek S, Babaliaros V, Ven F Le, Gleason TG, Chakravarty T, Szeto WY, Clavel MA, Agustin A de, Serra V, Schindler JT, Dahou A, Puri R, Pelletier-Beaumont E, Côté M, Pibarot P, et al. Transcatheter Aortic Valve Replacement in Patients With Low-Flow, Low-Gradient Aortic Stenosis: The TOPAS-TAVI Registry. J Am Coll Cardiol 2018;71:1297-1308.

6. Nitsche C, Scully PR, Patel KP, Kammerlander A, Koschutnik M, Dona C, Wollenweber T, Ahmed N, Thornton GD, Kelion A, Sabharwal N, Newton JD, Ozkor M, Kennon S, Mullen M, Lloyd G, Fontana M, Hawkins P, Pugliese F, Menezes L, Moon JC, Mascherbauer J, Treibel TA. Prevalence and Outcomes of Concomitant Aortic Stenosis and Cardiac Amyloidosis. J Am Coll Cardiol American College of Cardiology Foundation; 2020;

7. Lund O, Flo C, Jensen FT, Emmertsen K, Nielsen TT, Rasmussen BS, Hansen OK, Pilegaard HK, Kristensen LH. Left ventricular systolic and diastolic function in aortic stenosis. Prognostic value after valve replacement and underlying mechanisms. Eur Heart J 1997;

8. Delgado V, Tops LF, Bommel RJ Van, Kley F Van Der, Marsan NA, Klautz RJ, Versteegh MIM, Holman ER, Schalij MJ, Bax JJ. Strain analysis in patients with severe aortic stenosis and preserved left ventricular ejection fraction undergoing surgical valve replacement. Eur Heart J 2009;30:3037-3047. 
9. Vollema EM, Sugimoto T, Shen M, Tastet L, Ng ACT, Abou R, Marsan NA, Mertens B, Dulgheru R, Lancellotti P, Clavel MA, Pibarot P, Genereux P, Leon MB, Delgado V, Bax JJ. Association of left ventricular global longitudinal strain with asymptomatic severe aortic stenosis natural course and prognostic value. JAMA Cardiol 2018;3:839-847.

10. Yu CM, Sanderson JE, Marwick TH, Oh JK. Tissue Doppler Imaging. A New Prognosticator for Cardiovascular Diseases. J Am Coll Cardiol 2007;49:1903-1914.

11. Agricola E, Galderisi M, Oppizzi M, Schinkel AFL, Maisano F, Bonis M De, Margonato A, Maseri A, Alfieri O. Pulsed tissue Doppler imaqinq detects early myocardial dysfunction in asymptomatic patients with severe mitral regurgitation. Heart 2004;90:406-410.

12. Sanderson J. Heart failure with a normal ejection fraction. Heart. 2007.

13. Collier P, Phelan D, Klein A. A Test in Context: Myocardial Strain Measured by Speckle-Tracking Echocardiography. J Am Coll Cardiol 2017;69:1043-1056.

14. Lang RM, Badano LP, Mor-Avi V, Afilalo J, Armstrong A, Ernande L, Flachskampf FA, Foster E, Goldstein SA, Kuznetsova T, Lancellotti P, Muraru D, Picard MH, Rietzschel ER, Rudski L, Spencer KT, Tsang W, Voigt JU. Recommendations for Cardiac Chamber Quantification by echocardiography in adults (2015). Eur Heart J Cardiovasc Imaging 2015;16:233-270.

15. Baumgartner H, Falk V, Bax J, Bonis M De, Hamm C, Holm P, Lung B, Lancellotti P, Lansac E, Muñoz D, Rosenhek R, Sjögren J, Tornos Mas P, Vahanian A, Walther T, Wendler O, Windecker S, Zamorano J, Group ESD. 2017 ESC / EACTS Guidelines for the management of valvular heart disease The Task Force for the Management of Valvular Heart Disease of the European Society of Cardiology (ESC) and the European. Eur Heart J 2017;38:2739-2791.

16. O’Brien SM, Shahian DM, Filardo G, Ferraris VA, Haan CK, Rich JB, Normand SLT, DeLong ER, Shewan CM, Dokholyan RS, Peterson ED, Edwards FH, Anderson RP. The Society of Thoracic Surgeons 2008 Cardiac Surgery Risk Models: Part 2-Isolated Valve Surgery. Ann Thorac Surg 2009;88:S23-42.

17. Nashef SAM, Roques F, Michel P, Gauducheau E, Lemeshow S, Salamon R. European system for cardiac operative risk evaluation (EuroSCORE). Eur J Cardio-thoracic Surg 1999;1:9-13.

18. Kappetein AP, Head SJ, Généreux P, Piazza N, Mieghem NM Van, Blackstone EH, Brott TG, Cohen DJ, Cutlip DE, Es GA Van, Hahn RT, Kirtane AJ, Krucoff MW, Kodali S, MacK MJ, Mehran R, Rodés-Cabau J, Vranckx P, Webb JG, Windecker S, Serruys PW, Leon MB. Updated standardized endpoint definitions for transcatheter aortic valve implantation: The Valve Academic Research Consortium-2 consensus document. Eur Heart J 2012;33:2403-2418.

19. Herrmann S, Störk S, Niemann M, Lange V, Strotmann JM, Frantz S, Beer M, Gattenlöhner S, Voelker W, Ertl G, Weidemann F. Low-gradient aortic valve stenosis myocardial fibrosis and its influence on 
function and outcome. J Am Coll Cardiol 2011;

20. Everett RJ, Treibel TA, Fukui M, Lee H, Rigolli M, Singh A, Bijsterveld P, Tastet L, Musa T Al, Dobson L, Chin C, Captur G, Om SY, Wiesemann S, Ferreira VM, Piechnik SK, Schulz-Menger J, Schelbert EB, Clavel MA, Newby DE, Myerson SG, Pibarot P, Lee S, Cavalcante JL, Lee SP, McCann GP, Greenwood JP, Moon JC, Dweck MR. Extracellular Myocardial Volume in Patients With Aortic Stenosis. J Am Coll Cardiol 2020;75:304-316.

21. Dahl JS, Videbæk L, Poulsen MK, Rudbæk TR, Pellikka PA, Maller JE. Global strain in severe aortic valve stenosis relation to clinical outcome after aortic valve replacement. Circ Cardiovasc Imaging 2012;5:613-620.

22. Clavel MA, Berthelot-Richer M, Ven F Le, Capoulade R, Dahou A, Dumesnil JG, Mathieu P, Pibarot P. Impact of classic and paradoxical low flow on survival after aortic valve replacement for severe aortic stenosis. J Am Coll Cardiol 2015;65:645-653.

23. Clavel MA, Dumesnil JG, Capoulade R, Mathieu P, Sénéchal M, Pibarot P. Outcome of patients with aortic stenosis, small valve area, and low-flow, low-gradient despite preserved left ventricular ejection fraction. J Am Coll Cardio/ Elsevier Inc.; 2012;60:1259-1267.

24. Herrmann HC, Pibarot P, Hueter I, Gertz ZM, Stewart WJ, Kapadia S, Tuzcu EM, Babaliaros V, Thourani V, Szeto WY, Bavaria JE, Kodali S, Hahn RT, Williams M, Miller DC, Douglas PS, Leon MB. Predictors of mortality and outcomes of therapy in low-flow severe aortic stenosis: A placement of aortic transcatheter valves (PARTNER) trial analysis. Circulation 2013;127:2316-2326.

25. Argulian E, Chandrashekhar Y, Shah SJ, Huttin O, Pitt B, Zannad F, Bonow RO, Narula J. Teasing Apart Heart Failure with Preserved Ejection Fraction Phenotypes with Echocardiographic Imaging: Potential Approach to Research and Clinical Practice. Circ. Res. 2018.

26. Ross J. Afterload mismatch in aortic and mitral valve disease: Implications for surgical therapy. $J$ Am Coll Cardiol American College of Cardiology Foundation; 1985;5:811-826.

27. Calin A, Calin A, Mateescu AD, Mateescu AD, Popescu AC, Popescu AC, Bing R, Dweck MR, Popescu BA, Popescu BA. Role of advanced left ventricular imaging in adults with aortic stenosis. Heart 2020;106:962-969.

28. Clavel MA, Webb JG, Rodés-Cabau J, Masson JB, Dumont E, Larochellière R De, Doyle $D$, Bergeron S, Baumgartner H, Burwash IG, Dumesnil JG, Mundigler G, Moss R, Kempny A, Bagur R, Bergler-Klein J, Gurvitch R, Mathieu P, Pibarot P. Comparison between transcatheter and surgical prosthetic valve implantation in patients with severe aortic stenosis and reduced left ventricular ejection fraction. Circulation 2010;122:1928-1936. 
29. Sato K, Kumar A, Jones BM, Mick SL, Krishnaswamy A, Grimm RA, Desai MY, Griffin BP, Rodriguez LL, Kapadia SR, Obuchowski NA, Popović ZB. Reversibility of cardiac function predicts outcome after transcatheter aortic valve replacement in patients with severe aortic stenosis. J Am Heart Assoc 2017;6.

30. Attias D, MacRon L, Dreyfus J, Monin JL, Brochet E, Lepage L, Hekimian G, lung B, Vahanian A, Messika-Zeitoun D. Relationship between longitudinal strain and symptomatic status in aortic stenosis. $J$ Am Soc Echocardiogr Elsevier Inc; 2013;26:868-874.

31. Carstensen HG, Larsen LH, Hassager C, Kofoed KF, Jensen JS, Mogelvang R. Basal longitudinal strain predicts future aortic valve replacement in asymptomatic patients with aortic stenosis. Eur Heart $J$ Cardiovasc Imaging 2016;17:283-292.

\section{Tables}

Table 1. Distribution of baseline clinical characteristics in the overall study population and stratified by average $S^{\prime}$ status 
Overall population $(n=297)$
Average S'

$<6.5 \mathrm{~cm} / \mathrm{s}$ $(n=164)$
Average $S^{\prime} \geq 6.5$

$\mathrm{cm} / \mathrm{s}(\mathrm{n}=133)$ pvalue

$82 \pm 5$

$80 \pm 6$

0.898

84 (51.2)

$26.6 \pm 4.9$

66 (49.6)

0.816

$27.0 \pm 4.8$

$27.6 \pm 4.6$

0.907

Cardiovascular Risk Factors

\begin{tabular}{lllll}
\hline Smoker (\%) & $31(10.4)$ & $15(9.1)$ & $16(12)$ & 0.243 \\
\hline Hypertension (\%) & $257(86.5)$ & $144(87.8)$ & $113(85)$ & 0.498 \\
\hline Diabetes (\%) & $81(27.3)$ & $41(25)$ & $40(30.1)$ & 0.360 \\
\hline Dyslipidemia (\%) & $185(65.1)$ & $105(65.2)$ & $80(65)$ & 1.000 \\
\hline Medical History & & & $69(54.8)$ & 0.281 \\
\hline Known CAD (\%) & $143(51.1)$ & $74(48.1)$ & $10(7.5)$ & 0.004 \\
\hline Prior MI (\%) & $42(14.1)$ & $32(19.5)$ & $33(24.8)$ & 0.894 \\
\hline Prior PCI (\%) & $75(25.3)$ & $42(25.6)$ & $8(6.5)$ & 1.000 \\
\hline Prior CABG (\%) & $18(6.5)$ & $10(6.5)$ & $18(13.5)$ & 0.742 \\
\hline Prior stroke (\%) & $43(14.5)$ & $25(15.2)$ & $4(3)$ & 0.704 \\
\hline $\begin{array}{l}\text { Previous aortic valve } \\
\text { replacement (\%) }\end{array}$ & $7(2.4)$ & $3(1.8)$ & $8(10)$ & 0.041 \\
\hline Known PAD (\%) & $28(16.3)$ & $20(21.7)$ & $34(25.6)$ & 0.001 \\
\hline $\begin{array}{l}\text { Known Atrial Fibrillation } \\
\text { (\%) }\end{array}$ & $108(36.4)$ & $74(45.1)$ & &
\end{tabular}

Clinical Characteristics

\begin{tabular}{lllll} 
Sistolic BP $(\mathrm{mmHg})$ & $139 \pm 20$ & $134 \pm 19$ & $146 \pm 19$ & 0.758 \\
\hline Diastolic BP (mmHg) & $76 \pm 11$ & $75 \pm 11$ & $78 \pm 10$ & 0.365 \\
\hline Heart Rate $(\mathrm{bpm})$ & $70 \pm 13$ & $72 \pm 13$ & $68 \pm 12$ & 0.268 \\
\hline NYHA Class $(\%)$ & & & \\
$\mathbf{1}$ & & $17(10.4)$ & $21(15.8)$ \\
$\mathbf{2}$ & $38(12.8)$ & $55(33.7)$ & $43(32.3)$ & \\
$\mathbf{3}$ & $98(33.1)$ & $83(50.9)$ & $63(47.4)$ & \\
$\mathbf{4}$ & $146(49.3)$ & $8(4.9)$ & $6(4.5)$ & 0.284
\end{tabular}




\begin{tabular}{|lllll}
\hline COPD (\%) & $33(11.8)$ & $19(12.3)$ & $14(11.1)$ & 0.853 \\
\hline $\begin{array}{l}\text { Any conduction } \\
\text { disturbance (\%) }\end{array}$ & $98(37.1)$ & $54(37.8)$ & $44(36.4)$ & 0.898 \\
\hline PM/ICD at baseline (\%) & $31(11)$ & $22(14.1)$ & $9(7.1)$ & 0.084 \\
\hline Hb (gr/dL) & $12.5 \pm 1.8$ & $12.4 \pm 1.8$ & $12.5 \pm 1.8$ & 0.824 \\
\hline eGFR (Cockroft-Gault) & $55.2 \pm 16.4$ & $53.1 \pm 15.1$ & $57.9 \pm 17.6$ & 0.056 \\
\hline Dialysis (\%) & $5(1.8)$ & $3(1.9)$ & $2(1.6)$ & 1.000 \\
\hline HsTn (URL-fold) & $1.35(0.5-2.5)$ & $1.4(0.7-2.4)$ & $1.3(0.3-2.8)$ & 0.335 \\
\hline NT-proBNP (ng/dL) & $1820(615-4418)$ & $2370(776-$ & $1380(532-3630)$ & 0.157 \\
\hline
\end{tabular}

Risk Assessment

\begin{tabular}{lllll}
\hline EuroSCORE II & $4.3(2.6-7.2)$ & $4.9(2.8-8.3)$ & $3.7(2.3-5.9)$ & 0.051 \\
\hline STS-PROM & $4.4(2.8-6.7)$ & $4.6(3.2-7.0)$ & $3.9(2.2-6.4)$ & 0.365 \\
\hline Implanted prosthesis & & & & \\
\hline Balloon-expandable (\%) & $144(48.5)$ & $80(48.8)$ & $64(48.1)$ & \\
\hline Self-expanding (\%) & $153(51.5)$ & $84(51.2)$ & $69(51.9)$ & 1.000
\end{tabular}

Values are expressed as $\mathrm{n} / \mathrm{N}$ of patients (\%) or mean \pm standard deviation or median and interquartile range.

Abbreviations: $\mathrm{AV}=$ aortic valve; $\mathrm{BMI}=$ body mass index; $\mathrm{CABG}$ = coronary artery bypass grafting; $\mathrm{CAD}=$ coronary artery disease; $\mathrm{COPD}$ = chronic obstructive pulmonary disease; eGFR = estimated glomerular filtration rate; $I C D=$ implantable cardioverter defibrillator; $\mathrm{Hb}=$ haemoglobin; $\mathrm{HsTn}=$ high-sensitivity troponin; STS PROM = Society for Thoracic Surgery Predictive Risk of Mortality; MI = myocardial infarction; NYHA = New York Heart Association; $\mathrm{PCl}$ = percutaneous coronary intervention; $\mathrm{PAD}=$ peripheral artery disease; $\mathrm{PM}=$ pacemaker; $\mathrm{TAVI}$ = transcatheter aortic valve implantation; $\mathrm{URL}=$ Upper reference limit.

Table 2. Distribution of baseline echocardiographic characteristics in the overall study population and stratified by average $S^{\prime}$ status 
Overall population $(n=297)$
Average $S^{\prime}<6.5$

$\mathrm{cm} / \mathrm{s}$

$(n=164)$
Average $S^{\prime} \geq 6.5 \mathrm{~cm} / \mathrm{s}$ $(n=133)$

pvalue

Aortic Valve

Max AV gradient

$(\mathrm{mmHg})$

\section{Mean AV gradient}

$(\mathrm{mmHg})$

AVA (cm2)

$0.7 \pm 0.2$

$0.67 \pm 0.2$

$0.75 \pm 0.2$

$42.2 \pm 14.0$

$36.9 \pm 12.1$

$39.3 \pm 13.2$

$55.9 \pm 13.0$

$52.5 \pm 14.5$

$28.8 \pm 20.9$

$59.8 \pm 24.9$

$19.1 \pm 5.6$

$26.1 \pm 5.1$

$13.6 \pm 2.3$

$12.2 \pm 2.0$

$128.4 \pm 39.9$

LV mass index (g/m2)

Valves

AR $\geq$ moderate (\%)

56 (19.2)

$73(24.7)$

45 (15.4)

$33.2 \pm 23.3$

$63.4 \pm 26.1$

$20.2 \pm 5.6$

$27.3 \pm 5.5$

$13.9 \pm 2.6$

$12.3 \pm 2.1$

$138.1 \pm 41.3$

$33(20.6)$

54 (33.3)

35 (21.6)

TR $\geq$ moderate (\%)

Diastolic Function

E wave (cm/s)

$97.1 \pm 34.0$

E Deceleration Time (s) $\quad 0.2 \pm 0.1$

A wave $(\mathrm{cm} / \mathrm{s})$

$100.4 \pm 35.3$

E/A ratio

$1.1 \pm 0.9$

$6.7 \pm 2.2$

236 (89.1)

$6.1 \pm 1.9$
Lateral e' (cm/s)

Septal e' (cm/s)

Average e' (cm/s)
$91.8 \pm 36.0$

0.565

$0.2 \pm 0.1$

$0.2 \pm 0.1$

0.784

$92.5 \pm 36.1$

$109.1 \pm 32.6$

0.293

$1.3 \pm 1.1$

$0.9 \pm 0.4$ $<0.001$

$6.6 \pm 2.3$

$6.9 \pm 2.2$

0.561

136 (91.9)

$100(85.5)$

0.114

$5.8 \pm 1.8$

$6.4 \pm 1.9$

0.988
$101.4 \pm 31.6$ 


\section{E/e' ratio}

$17.2 \pm 7.6$

$18.8 \pm 7.8$

$15.1 \pm 6.7$

0.141

TDI-derived longitudinal systolic function

\begin{tabular}{|c|c|c|c|c|}
\hline $\begin{array}{l}\text { Septal mitral annular } \mathrm{S}^{\prime} \\
(\mathrm{cm} / \mathrm{s})\end{array}$ & $5.7 \pm 1.7$ & $4.7 \pm 0.9$ & $7.0 \pm 1.5$ & 0.001 \\
\hline $\begin{array}{l}\text { Lateral mitral annular } \\
S^{\prime}(\mathrm{cm} / \mathrm{s})\end{array}$ & $6.9 \pm 1.7$ & $5.8 \pm 1.2$ & $8.2 \pm 1.3$ & 0.080 \\
\hline $\begin{array}{l}\text { Average mitral annular } \\
\mathrm{S}^{\prime}(\mathrm{cm} / \mathrm{s})\end{array}$ & $6.2 \pm 1.6$ & $5.1 \pm 0.9$ & $7.6 \pm 1.1$ & 0.259 \\
\hline
\end{tabular}

Others

\begin{tabular}{lllll}
\hline LAVi $(\mathrm{ml} / \mathrm{m} 2)$ & $49.9 \pm 20.1$ & $53.5 \pm 22.2$ & $45.3 \pm 16.2$ & 0.010 \\
\hline sPAP $(\mathrm{mmHg})$ & $38.3 \pm 14.5$ & $42.0 \pm 15.7$ & $33.8 \pm 11.3$ & 0.001 \\
\hline TAPSE $(\mathrm{mm})$ & $20.5 \pm 4.9$ & $19.6 \pm 4.4$ & $21.6 \pm 5.4$ & 0.239 \\
\hline Pericardial effusion $(\%)$ & $31(11)$ & $17(10.8)$ & $14(11.3)$ & 1.000 \\
\hline CVP $(\%)$ & & & \\
\hline $\mathbf{3}$ & & $87(77.7)$ & $79(89.8)$ & \\
\hline $\mathbf{8}$ & $166(83)$ & $10(8.9)$ & $3(3.4)$ & 0.125 \\
\hline $\mathbf{1 5}$ & $13(6.5)$ & $15(13.4)$ & $6(6.8)$ & \\
\hline
\end{tabular}

Values are expressed as $\mathrm{n} / \mathrm{N}$ of patients (\%) or mean \pm standard deviation.

Abbreviations: $A R=$ aortic regurgitation; $A V=$ aortic valve; $A V A=$ aortic valve area; $C V P=$ central venous pressure; iLEDV = indexed left ventricle end-diastolic volume; iLVESV = indexed left ventricle end-systolic volume; iTDD = indexed tee-diastolic volume; iTSD = indexed tele-systolic diameter; IVS = interventricular septum; $L A V i=$ left atrial volume indexed; $L V E F=$ left ventricle ejection fraction; $M R=$ mitral regurgitation; SPAP = systolic pulmonary artery pressure; $\mathrm{PW}=$ posterior wall; TAPSE = tricuspid annular plane systolic excursion; TDI = tissue doppler imaging; $\mathrm{TR}$ = tricuspid regurgitation; $\mathrm{SVi}$ = stroke volume index;

\section{Table 3. Short- and Long-Term Clinical Outcomes according to average $S^{\prime}$ status}




\section{Bleeding (\%)}

All-cause Death (\%)

Life-threatening

Major

AKI stage 2-3 (\%)

Vascular Complications (\%)

Major

Minor

Myocardial Infarction (\%)

Stroke/TIA (\%)

New Pacemaker (\%)

Coronary Obstruction (\%)

All-cause Death (\%)

HF Hospitalitazion (\%)

Stroke/TIA (\%)

Disabling stroke

Endocarditis (\%)

THV Thrombosis (\%)

NYHA class (\%)

\section{1}

2

3

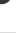

1
2
3

All-cause Death (\%)

A-cause Death/HF hosp. (\%) 31 (19.6)
Average $\mathrm{S}^{\prime}<6.5 \mathrm{~cm} / \mathrm{s}$ $(n=164)$

\section{0-DAY OUTCOMES}

$4(2.5)$

$1(0.8)$

0.383

Average $S^{\prime} \geq 6.5 \mathrm{~cm} / \mathrm{s}(\mathrm{n}=133) \quad$ P-value

$3(1.9)$

8 (6)

0.201

$10(6.2)$

7 (5.3)

0.424

$2(1.2)$

$3(2.3)$

0.661

$15(9.3)$

$14(10.6)$

0.910

19 (11.8)

$13(9.8)$

0.736

0 (0)

$1(0.8)$

0.451

$3(1.8)$

$2(1.5)$

1.000

19 (11.8)

$20(15.2)$

0.490

$0(0)$

$1(0.8)$

0.451

\section{1-YEAR OUTCOMES}

18 (11.5)

$6(4.9)$

0.055

$14(9.1)$

$17(13.8)$

0.252

4 (2.5)

2 (2.4)

0.639

1 (0.6)

$1(0.8)$

0.859

1 (0.6)

4 (3.3)

0.174

3 (1.9)

$4(3.3)$

0.703

$\begin{array}{ll}78(56.1) & 61(52.6) \\ 56(40.3) & 46(39.7) \\ 5(3.6) & 8(6.9)\end{array}$

0.499

\section{LONG-TERM OUTCOMES}

28 (17.1\%)

$\begin{array}{ll}8(6.1 \%) & 0.003 \\ 13(10.2) & 0.020\end{array}$


Values are expressed as $\mathrm{n} / \mathrm{N}$ of patients (\%)

Abbreviations: $\mathrm{AKI}=$ acute kidney injury; THV = transcatheter heart valve. Other abbreviations as in table 1.

Table 4. Predictive factors for long-term all-cause mortality and all-cause mortality or heart failure hospitalization 
ALL-CAUSE MORTALITY*

\begin{tabular}{|c|c|c|c|c|}
\hline & \multicolumn{2}{|l|}{ UNIVARIATE } & \multicolumn{2}{|l|}{ MULTIVARIATE } \\
\hline & $\mathrm{HR}(95 \% \mathrm{Cl})$ & $\mathbf{p}$ & $\mathrm{HR}(95 \% \mathrm{Cl})$ & $\mathbf{p}$ \\
\hline Age (yrs) & $1.07(1.00 \pm 1.15)$ & 0.046 & & \\
\hline $\mathrm{Hb}(\mathrm{gr} / \mathrm{dL})$ & $0.81(0.66 \pm 0.99)$ & 0.041 & & \\
\hline Known atrial fibrillation & $2.08(1.08 \pm 4.01)$ & 0.028 & & \\
\hline eGFR (Cockroft-Gault) & $0.98(0.96 \pm 1.00)$ & 0.056 & & \\
\hline Euroscore II (\%) & $1.06(1.02 \pm 1.10)$ & 0.002 & $1.05(1.01-1.09)$ & 0.009 \\
\hline Mean AV gradient (mmHg) & $0.98(0.95 \pm 1.00)$ & 0.091 & & \\
\hline Septal e' (cm/sec) & $0.79(0.62 \pm 1.02)$ & 0.066 & & \\
\hline Average $\mathrm{S}^{\prime}<6.5 \mathrm{~cm} / \mathrm{s}$ & $2.38(1.08 \pm 5.23)$ & 0.030 & $2.69(1.22-5.93)$ & 0.014 \\
\hline \multirow[t]{4}{*}{$\mathrm{TR} \geq$ moderate } & $1.68(1.15 \pm 2.45)$ & 0.007 & & \\
\hline & \multicolumn{4}{|c|}{ ALL-CAUSE MORTALITY/ HF HOSPITALIZATION* } \\
\hline & UNIVARIATE & & MULTIVARIATE & \\
\hline & $\mathrm{HR}(95 \% \mathrm{Cl})$ & $\mathbf{p}$ & $\mathrm{HR}(95 \% \mathrm{Cl})$ & $\mathbf{p}$ \\
\hline Age (yrs) & $1.07(1.00 \pm 1.15)$ & 0.046 & & \\
\hline $\mathrm{Hb}(\mathrm{gr} / \mathrm{dL})$ & $0.81(0.66 \pm 0.99)$ & 0.041 & & \\
\hline Known atrial fibrillation & $2.08(1.08 \pm 4.01)$ & 0.028 & & \\
\hline eGFR (Cockroft-Gault) & $0.98(0.96 \pm 1.00)$ & 0.056 & & \\
\hline Euroscore II & $1.06(1.02 \pm 1.10)$ & 0.002 & & \\
\hline Mean AV gradient (mmHg) & $0.98(0.95 \pm 1.00)$ & 0.091 & $0.97(0.94-0.99)$ & 0.018 \\
\hline Septal e' (cm/sec) & $0.79(0.62 \pm 1.02)$ & 0.066 & & \\
\hline Average $\mathrm{S}^{\prime}<6.5 \mathrm{~cm} / \mathrm{s}$ & $2.38(1.08 \pm 5.23)$ & 0.030 & $2.01(1.05-3.83)$ & 0.035 \\
\hline TR $\geq$ moderate & $1.68(1.15 \pm 2.45)$ & 0.007 & & \\
\hline
\end{tabular}

* median follow-up: 540 (363-540) days.

Abbreviations: $\mathrm{Cl}=$ Confidence Interval, $\mathrm{HR}=$ Hazard Ratio. Other abbreviations as in Tables 1 and 2.

\section{Figures}




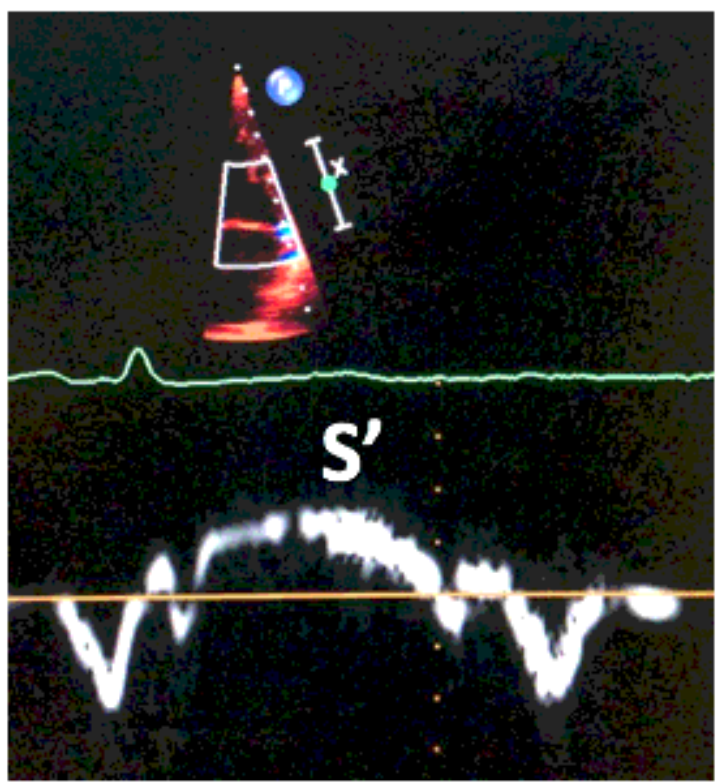

LATERAL $\mathbf{S}^{\prime}$

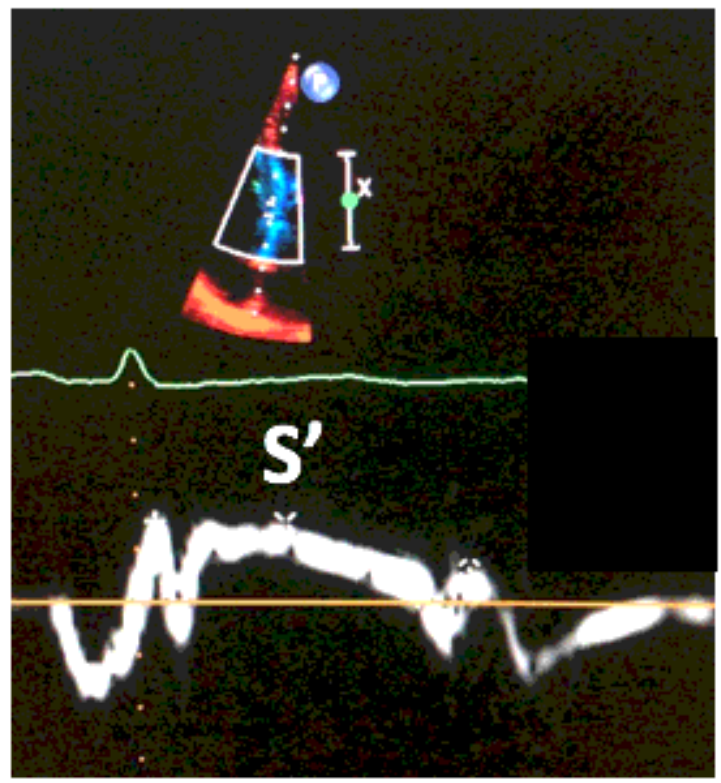

SEPTAL $\mathbf{S}^{\prime}$

\section{Figure 1}

Measurement of peak systolic $\left(S^{\prime}\right)$ velocities by 2-dimensional tissue Doppler imaging. $S^{\prime}$ represents the peak myocardial longitudinal systolic shortening velocity during ejection assessed by TDI. S' velocities are measured at the level of the lateral (left panel) and medial (right panel) mitral annulus by pulsed-wave TDI from the apical four-chamber view. Average $S^{\prime}$ is calculated as the mean of the lateral and medial $S^{\prime}$ velocities. TDI is performed adjusting gain and frame rate to get an appropriate tissue characterization. 


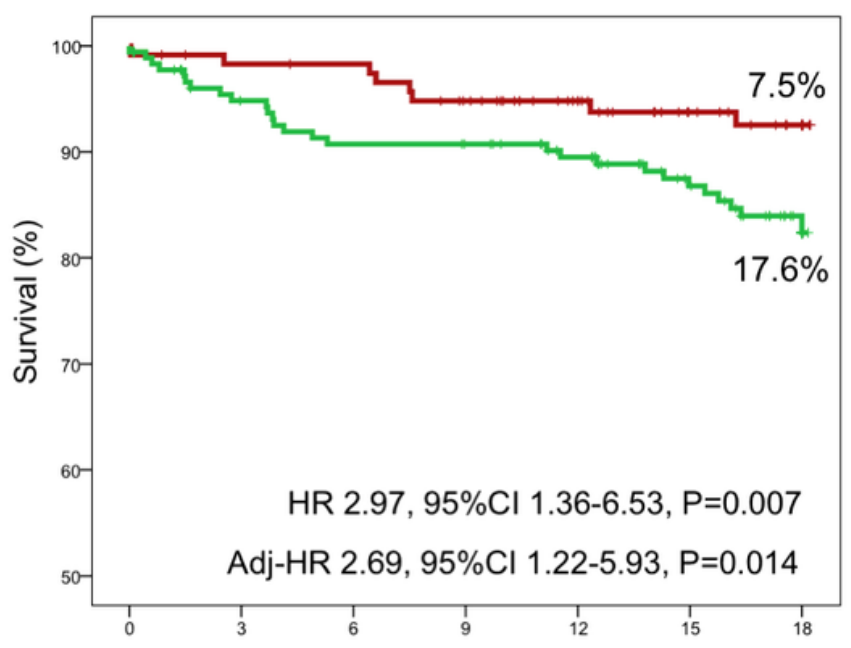

Months from TAVI

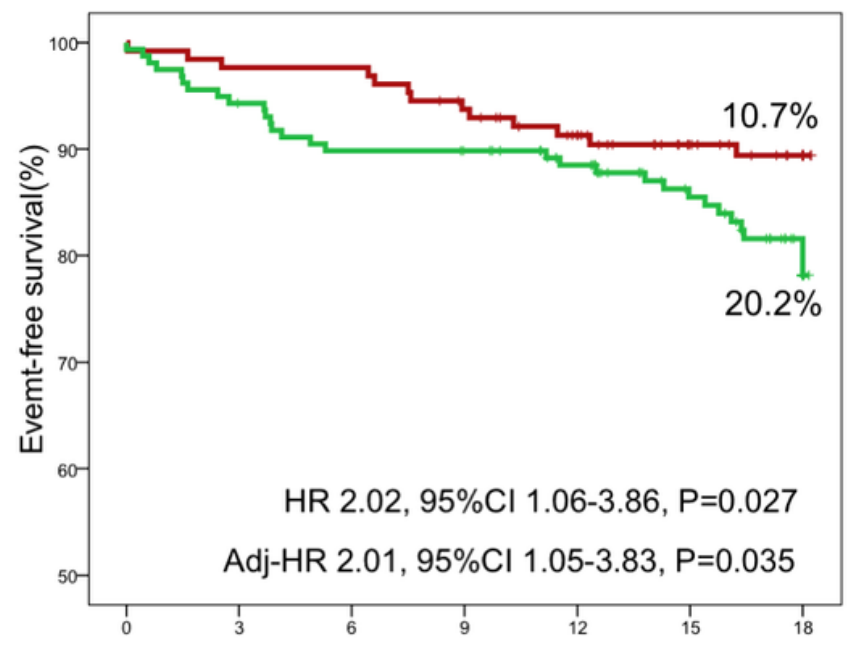

Months from TAVI

Average $\mathrm{S}^{\prime} \geq 6.5 \mathrm{~cm} / \mathrm{sec}$

Average $\mathrm{S}^{\prime}<6.5 \mathrm{~cm} / \mathrm{sec}$

Figure 2

Kaplan Meier curves for all-cause mortality and all-cause mortality or heart failure hospitalization at 540 days follow-up stratified by average $S^{\prime}$. Abbreviations as in Tables 1 and 3 . Hazard ratios are derived from Cox proportional hazard models.
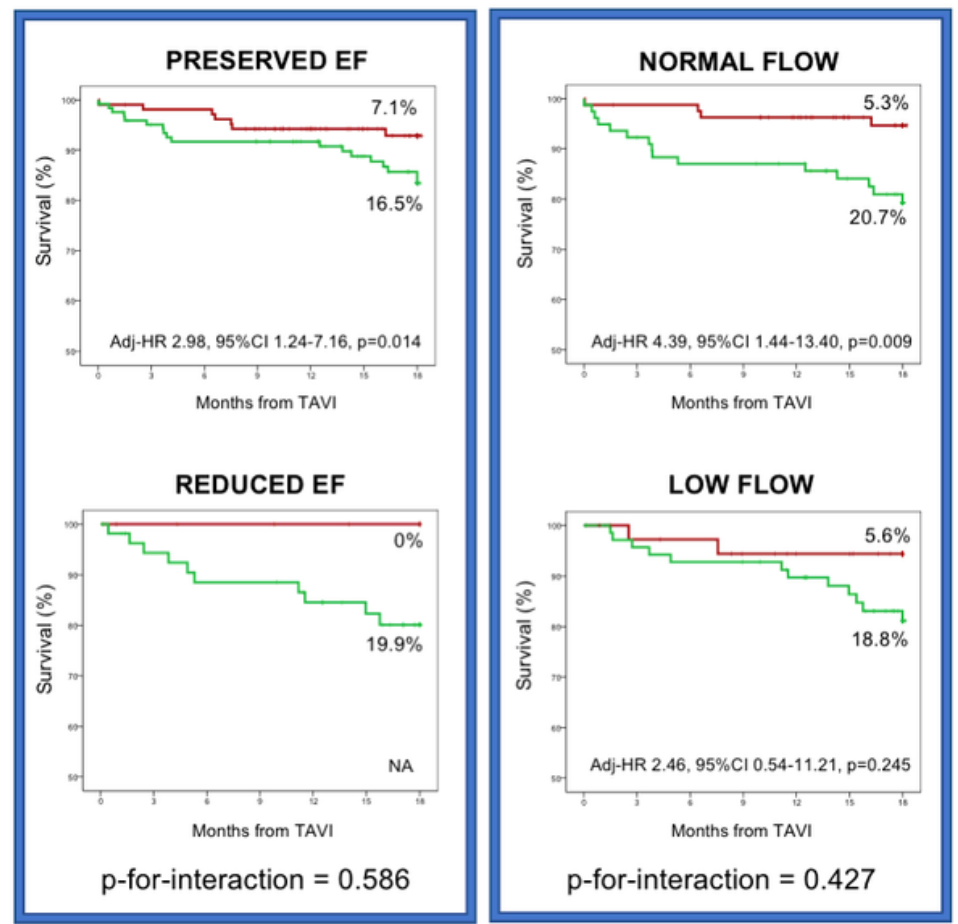

Average $S^{\prime} \geq 6.5 \mathrm{~cm} / \mathrm{sec}$
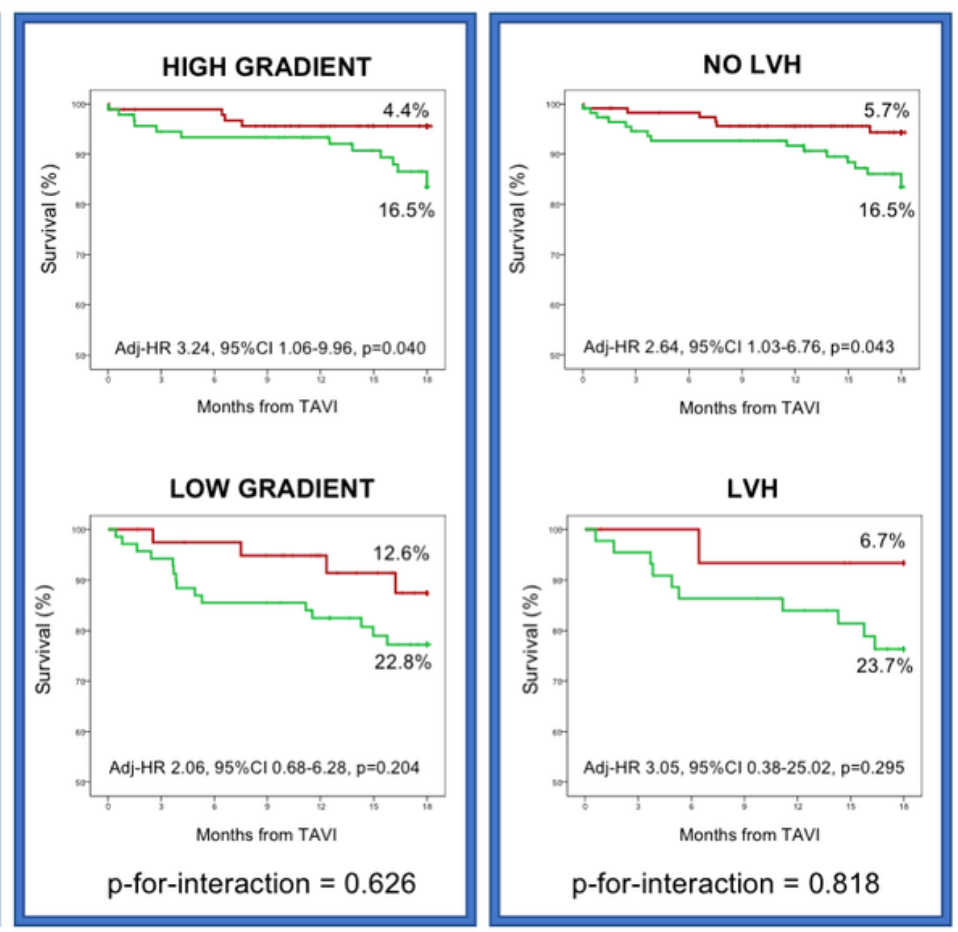

Average S' $<6.5 \mathrm{~cm} / \mathrm{sec}$ 


\section{Figure 3}

Association of average $S^{\prime}$ with all-cause mortality across subgroups Black squares represent hazard ratios (HR); horizontal black lines illustrate $\mathrm{Cl}$. *Interaction $\mathrm{P}$ testing for an effect modification of the subgroups on the difference in all-cause death between average $S^{\prime}<6.5 \mathrm{~cm} / \mathrm{sec} v \mathrm{~s}$. $\geq 6.5 \mathrm{~cm} / \mathrm{sec}$. Abbreviations as in Tables 1 and 2.

\section{Supplementary Files}

This is a list of supplementary files associated with this preprint. Click to download.

- SUPPLEMENTARYAPPENDIX.docx 